\title{
TRATA DE SERES HUMANOS Y CRIMINALIDAD ORGANIZADA TRANSNACIONAL: PROBLEMAS DE POLÍTICA CRIMINAL DESDE LOS DERECHOS HUMANOS*
}

\section{Laura Zúñiga Rodríguez**}

"El oficio más viejo del mundo no es la prostitución, sino mirar para otro lado",

Resumen: En este trabajo pretendo poner de manifiesto las dificultades del tratamiento jurídico del delito de la trata de seres humanos, especialmente porque es un fenómeno invisible, dado que discurre en muchos casos detrás de negocios lícitos, como bares, clubs de alterne, etc. La problemática de su tratamiento penal radica en que es un fenó-

Recibido: febrero 2018. Aceptado: noviembre 2018

* Este trabajo se inscribe dentro del Proyecto DER2016-79705-R, "Criminalidad organizada, terrorismo y responsabilidad penal de las personas jurídicas", financiado por el Ministerio de Economía y Competitividad.

** Catedrática de Derecho Penal. ORCID ID: 0000-0002-8696-8025 Departamento de Derecho Público General, Facultad de Derecho de la Universidad de Salamanca. Campus Miguel de Unamuno s.n, 37071 Salamanca.Email: 1zr@usal.es

1 Testimonio de una mujer tratada, El País, "5.660 víctimas de esclavitud afloran tras las reformas de los últimos años”. Reportaje del 17 de abril de 2017. https://politica.elpais.com/politica/2017/04/14/actualidad/1492152357_266303.html?rel=mas revisado 28 de agosto de 2017. 
meno en el que se encuentran ambivalencias, intereses contrapuestos, generalizaciones que impiden ver individualidades, dado que se esconde tras otros fenómenos como la prostitución, la explotación sexual, la inmigración clandestina. Ello ha dado lugar a políticas criminales contradictorias que vulneran los derechos de las víctimas. El análisis se centra en el supuesto de trata abusiva con fines de explotación sexual por vulnerabilidad de la víctima, por considerar que es donde realmente pueden darse casos problemáticos para diferenciar prostitución libre y prostitución coactiva, ya que la víctima, por encontrarse en situación de necesidad, no tiene plena autonomía de la voluntad. De acuerdo con los Convenios Internacionales, se considera que en este delito se protege un derecho humano, la dignidad humana, que posee una intangibilidad más allá de la voluntad personal cuando existen condiciones objetivas de explotación sexual.

Palabras clave: trata de seres humanos, derechos humanos, criminalidad organizada transnacional, prostitución, explotación sexual, vulnerabilidad, dignidad humana.

\title{
TRAFFICKING IN HUMAN BEINGS AND TRANSNATIONAL ORGANIZED CRIMINALITY: PROBLEMS OF CRIMINAL POLICY FROM HUMAN RIGHTS
}

\begin{abstract}
This paper intends to highlight the difficulties of the legal treatment of the crime of trafficking in human beings, especially because it is an invisible phenomenon, mostly because in many cases, it takes place behind legal businesses, such as bars, clubs, etc. The problem of its criminal treatment is that it is a phenomenon full of ambivalences, conflicting interests, and generalizations that prevent seeing individualities, since it is concealed by other phenomena such as prostitution, sexual exploitation and illegal immigration. This has led to contradictory criminal policies that violate the rights of victims. The analysis focuses on the case of abusive trafficking for the purpose of sexual exploitation due to the vulnerability of the victim, considering that it is in those cases where the difficulty of differentiating between free prostitution and coercive prostitution arises, since the victim due to being in a situation of need, does not have full autonomy of her will. In accordance with International Conventions, human dignity, as a human right is protected, which is intangible, in disregard of the personal will, when there are objective conditions of sexual exploitation.
\end{abstract}

Keywords: trafficking in human beings, human rights, transnational organized crime, prostitution, sexual exploitation, vulnerability, human dignity. 


\section{Introducción}

En España se introdujo en el Código Penal el delito de trata de seres humanos en el art. 177 bis con la reforma de 2010, completando estos cambios legislativos con la reforma de 2015. Por tanto, son pocos los años de rodaje de la criminalización expresa de la trata de personas en nuestro país y, según datos del CITCO (Centro de Inteligencia contra el Terrorismo y el Crimen Organizado), ello ha permitido a las fuerzas del orden intervenir y rescatar de la situación de esclavitud a 5.600 personas entre los años 2012-2016: 4.430 víctimas de trata y explotación sexual, o solo de este segundo delito, de 2012 a 2016. Si se suman las de explotación laboral, perseguida con más ahínco desde 2015 , ascienden a 5.675 personas $^{2}$. Esta primera aproximación al problema nos presenta las siguientes interrogantes $i$ Antes no ha existido este fenómeno? ¿Qué papel ha jugado la ley penal para su visibilidad? ¿Resulta efectiva la regulación penal? Y algunas primeras respuestas: se demuestra que claramente de las diversas formas de trata, la trata con fines de explotación sexual resulta ampliamente mayoritaria.

Por supuesto que este trabajo de enfoque jurídico-penal no pretende dar respuestas a dichas interrogantes, pero sí tiene como objetivo poner en el centro de mira diversos aspectos que muestran que estamos ante un fenómeno complejo, poliédrico, en el que recurrentemente se encuentran ambivalencias, intereses contrapuestos, que dificultan su tratamiento y, por tanto, su persecución. Las definiciones de la ley, con su necesidad de establecer generalizaciones, abstracciones, parece olvidar situaciones concretas, voluntades personales. Pero de otro lado, gracias a la fuerza de la ley penal se ha podido perseguir situaciones insostenibles de violaciones a los derechos humanos, principalmente de mujeres y niños. Nos encontramos en muchos supuestos de casos límites, donde no es fácil saber la voluntariedad del comportamiento de la persona tratada. Y, no menos importante, la visión que el intérprete tenga de la prostitución (telón de fon-

2 Ob. ult. cit. 
do de la trata con fines de explotación sexual), condiciona el tratamiento de la trata de personas, especialmente en lo que se refiere a la utilización de la persecución penal.

De todo este conjunto de problemas que se plantean a partir del abordaje de la trata de seres humanos, me centraré en la trata abusiva con fines de explotación sexual, dado que es imposible en un artículo agotar las inmensas dimensiones del fenómeno. Ello porque, como se ha visto, la trata con fines de explotación sexual es la que se presenta en la realidad con cifras escandalosas en todo el mundo. Asociada a la denominada "industria del sexo" o "negocio del sexo", se encuentran en el escenario social una amalgama de conductas donde las fronteras entre lo querido e impuesto no son nítidas, o lo prohibido y lo permitido se encuentran en una delgada línea roja. Para ejemplificar, un conocido caso en España: el caso Torbe. El conocido como "rey del porno español" fue imputado en abril de 2016 por delitos de pornografía infantil, abuso de menores, trata de seres humanos, blanqueo de capitales y delitos contra la Hacienda Pública. A los pocos meses salió de la cárcel con una fianza de 100.000 euros (el proceso aún está en marcha). También fue detenido su socio ucraniano Boris con el que había iniciado un negocio para grabar "Bukkakes", práctica sexual colectiva, en España con mujeres que su socio contrataba en su país de origen. Las imputaciones se sustentaron en las declaraciones de tres testigos protegidas, entre ellas una menor, que luego se desdijeron de sus primeras declaraciones, aduciendo que las prácticas sexuales eran consentidas. En el caso de la menor ésta sostuvo que le dio un DNI falso (sic) y, por tanto, Torbe no sabía que era menor. Pero los primigenios testimonios de tres chicas que accedieron a realizar un reportaje para El País, son absolutamente desgarradores y verosímiles, de cómo les obligaban a prácticas sexuales exageradas, sin cuidados sanitarios (con analíticas falsas), llegando a vomitar y llorar ${ }^{3}$, donde el trato ve-

3 El Pais, "Yo trabajé para Torbe. Tres chicas relatan a EL PAÍS su sórdida experiencia con el rey del porno español imputado y encarcelado por delitos de difusión de pornografía". https://elpais.com/ccaa/2016/06/14/catalunya/1465919624_004283.html revisado 29-08.17 
jatorio está clarísimo. Uno se pregunta por qué están esas chicas en ese lugar, realizando ese trabajo, ya que supuestamente nadie las obliga y las dificultades para comprender que se trata de prácticas totalmente consentidas se hacen evidentes. Por supuesto que habrá casos de mujeres que acceden a realizar estas conductas con total voluntariedad, pero lo que se trata para el Derecho es de proteger a las personas que son sometidas por otras, que son obligadas a realizar conductas que no quieren $y$, concretamente en la trata, de no permitir la cosificación de la persona, al punto de convertirse en un bien de lucro para el tratante. Como sostiene FERRAJOLI, los derechos y garantías son la ley del más débil ${ }^{4}$, de ahí que me parezca interesante adentrarme en el discutido concepto de vulnerabilidad de la víctima, que ha sido valorado tanto positiva como negativamente por la doctrina. Todo ello nos llevará a tratar la dignidad como bien jurídico protegido y especialmente su disponibilidad (otro tema controvertido) que tendrá incidencia en la persecución penal, incluso vinculado a los aspectos probatorios.

Si los Estados se comprometen a nivel internacional a prevenir, perseguir y proteger a las víctimas de trata, como se desprende del Protocolo de Palermo de 2000 y de la Directiva 2011/36/UE, relativa a la prevención y lucha contra la trata de seres humanos y la protección de las víctimas, es clave comprender el alcance de estos conceptos porque de ello depende especialmente la persecución penal, la posibilidad de castigar o no ciertas conductas límite, de realizar verdaderamente o no una interpretación en favor de las víctimas de trata. Ello porque los casos de coacción, violencia o engaño suelen ser más evidentes, en cambio los supuestos de abuso o vulnerabilidad de la víctima no resultan muchas veces claros. Máxime en un terreno como es la explotación sexual donde no existen, como sería en la explotación laboral con las leyes laborales y los umbrales mínimos de protección, delimitaciones nítidas.

4 FERRAJOLI, Luigi, Derechos y garantías. La ley del más débil, Madrid, Trotta, 1999, passim. 
Para realizar este abordaje, empezaré por incidir en algunos datos de la trata de seres humanos en el contexto global y en España concretamente, que nos enseñan que estamos ante un fenómeno significado, lamentablemente, del momento actual. Diversas cifras indican que se trata del negocio ilícito que disputa el segundo puesto en la escala global ${ }^{5}$ de tráficos ilícitos al tráfico de armas, después del tráfico de drogas. Por tanto, se trata de un comercio ilícito que mueve muchísimo dinero, según datos de la Oficina de Naciones Unidas para la Droga y el Delitos (UNODC), se estima en unos 32 billones de dólares. Según Información de la Iniciativa Global contra la Trata de Personas (UNGIFT), de las ganancias globales que se mueven detrás del mercado ilícito de la trata de personas 1.3 billones de dólares que equivalen al 4.1\% son generados en América Latina. El 49\% se genera en países industrializados caracterizados por ser los principales destinos de las víctimas que provienen de Latinoamérica $^{6}$. Ello muestra que el negocio de la trata a nivel mundial se presenta de países de origen de las víctimas de países pobres, a países de destino de los consumidores de países ricos.

\section{La trata de seres humanos en el contexto global}

La trata de seres humanos es un fenómeno que expresa todas las complejidades de la globalización. De acuerdo con el profesor de Palermo, MILITELLO, "la trata de seres humanos es una de las manifestaciones más típicas de la criminalidad contemporánea: es una criminalidad de los beneficios, es una criminalidad de género y es una criminalidad de carácter transnacional" ". Como en otros tráficos ilícitos, la lógica de los

5 A decir verdad estas cifras suelen tener en cuenta la mixtura entre tráficos ilícitos de personas y trata de seres humanos que, aunque fenómenos diferentes, en la realidad se encuentran en muchos casos vinculados, como enseguida se verá.

6 https://www.unodc.org/documents/lpo-brazil/sobre-unode/Fact_Sheet_Dados_Trafico_de_Pessoas_geral_ESP.pdf,p. 2, revisado 30.08.2017.

7 MILITELLO, "La tratta di esseri humani: la Politica Criminale multilivello e la problematica distinzione con il traffico di migranti", en Rivista italiana di Diritto e Procedure Penale, Anno LXI - Fasc. 1, 2018, p. 87. 
traficantes es la misma: ubicar zonas de bajo riesgo, donde poseen un control relativo del entorno institucional como países de oferta, mientras que buscan sus mercados preferentes en las zonas de demanda más rica, a fin de cobrar precios más altos ${ }^{8}$. La explotación sexual, laboral y otras formas de explotación de los seres humanos responde a escala global a la misma metodología de actuación de los mercados ilícitos: la oferta y la demanda, de zonas pobres a zonas ricas, de aprovechamiento de países o zonas con debilidad institucional ya sea por guerras, hambre, catástrofes naturales o inexistencia del Estado. La criminalidad organizada transnacional se expresa en la realización de estas redes de intercambio de los tráficos ilícitos, aprovechando las rutas de otros tráficos, subcontratando, intercambiando información, intercambiando negocios ilícitos, en lo que Castells denomina el crimen global ${ }^{9}$.

En primer lugar, debe reconocerse que en el contexto global la trata de personas (trafficking in persons) se vincula a otro fenómeno criminal, el tráfico de personas (migrants smuggling), pues los traficantes aprovechan los flujos migratorios que en realidad son redes para los movimientos de personas para realizar el comercio con seres humanos ${ }^{10} \mathrm{y}$, por tanto, participa de los mismos detonantes: pobreza, marginalidad, falta de expectativas, conflictos sociales y políticos, guerras, enfermedades, del lado de la oferta. Del lado de la demanda, sociedades opulentas, con déficit en su crecimiento demográfico, en las que los nacionales

8 CASTELLS, La era de la información. Fin de milenio. Vol. 3, Barcelona, Alianza Editorial, 2001, p. 201. Más extensamente Vid. el Capítulo 3, "La conexión perversa: la economía criminal global", donde se pone de relieve que en las últimas décadas las organizaciones criminales han llevado a cabo sus operaciones cada vez más a escala transnacional.

9 Ob. ult. cit., p. 199: "el delito global, la interconexión de poderosas organizaciones criminales y sus asociados en actividades conjuntas por todo el planeta es un nuevo fenómeno que afecta profundamente a la economía, la política y la seguridad nacionales e internacionales".

10 Cfr. sobre estos temas de manera monográfica: PÉREZ CEPEDA, Globalización, tráfico internacional ilícito de personas y derecho penal, Granada, Comares, 2004, passim. 
no están dispuestos a realizar determinados trabajos y en las que la gratificación sexual resulta complicada por el aislamiento y el egoísmo propio del bienestar entendido como riqueza material ${ }^{11}$. La mayoría de las personas tratadas provienen de los países más pobres del mundo y dentro de los propios países (tráfico interno) también los movimientos se dan de zonas pobres a zonas ricas. Destacable es que la mayoría de víctimas detectadas provienen del África subsahariana y del este de Asia, según el último Informe de UNODC ${ }^{12}$.

Ciertamente que estas vinculaciones están asociadas a las características de las nuevas organizaciones criminales a escala global, esto es, a la llamada criminalidad organizada transnacional que posee un sistema de red flexible para asociarse a diferentes formas de criminalidad y desvincularse según los intereses concretos. De ahí que los grupos criminales de carácter internacional se dediquen a varios tipos de delitos, siendo los más próximos, tráfico de personas y trata de seres humanos. Así, el Informe de la UE SOCTA (Serious and Organised Crime Threat Assesment) de 2017, señala que "el 45\% de las organizaciones criminales reportadas, participan en más de una actividad criminal. La proporción de estos ha aumentado considerablemente en comparación con 2013. Las organizaciones criminales también suelen participar en más de una actividad delictiva para mitigar los riesgos, reducir los costos operativos y aumentar márgenes de beneficio. Muchos grupos criminales son altamente flexibles y capaces de pasar de una actividad delictiva a otra o añadir nuevas actividades delictivas a su cartera de delitos. Algunas organizaciones criminales funcionan bajo demanda y sólo se activan una vez que surgen nuevas oportunidades" 13 .

11 Para PÉREZ CEPEDA, Globalización, tráfico internacional ilicito de personas y derecho penal, ob.cit., p. 33, "en los países industrializados una tendencia a demandar mano de obra para trabajos poco cualificados, placeres sexuales a bajo precio, etc...".

12 UNODC, Global Repport on traffiching in persons, 2016, p. 5. Un total de 69 países reportaron víctimas del África subsahariana.

13 UE, Serious and Organised Crime Threat Assesment, SOCTA, 2017, p. 15. 
Efectivamente, uno de los problemas del abordaje político-criminal de la trata de seres humanos cuando se hace a nivel transnacional es precisamente esa vinculación con los tráficos ilícitos de personas o con los movimientos migratorios. A nadie escapa que el inmenso negocio del tráfico de personas, del aprovechamiento de los flujos migratorios por guerras, miserias o catástrofes de las organizaciones criminales internacionales, esconde también la trata de seres humanos, porque las personas en ese proceso de inmigración forzado se exponen al fraude, al abuso, la violencia y a la muerte, presentándose como personas vulnerables para ser presa de los comerciantes de seres humanos. Especialmente cuando el abordaje político-criminal es desde los autores de la trata, la aproximación suele ser represiva, centrándose en la persecución de las organizaciones criminales que realizando tráficos ilícitos de migrantes, encubren conductas de explotación sexual, laboral o de otra índole, convirtiéndose en un verdadero tráfico de seres humanos ${ }^{14}$.

Todos los informes sobre la trata de personas se han hecho eco de esta proximidad entre ambos fenómenos que, en muchos casos, han marcado lineamientos de Política Criminal contradictorios. El informe SOCTA 2017 de la UE señala que las organizaciones criminales involucradas en trata de seres humanos a menudo explotan a los inmigrantes, especialmente a las víctimas de tránsito dentro de la UE. "Los migrantes irregulares representan un gran grupo de víctimas potenciales susceptibles de promesas de trabajo incluso si implica la explotación" ${ }^{15}$. Efectivamente, la explotación laboral que el Informe de UNODC ha puesto en evidencia como un fenómeno en alza, se relaciona mayoritariamente con la inmigración irregular. Los inmigrantes, tanto hombres como mujeres, pueden ser objeto de las mafias, de empresarios inescrupulosos que aprovechan dicha

14 Sobre las dificultades para deslindar ambos fenómenos cuando se pretende una aproximación holística de la trata Vid. MILITELLO, "La tratta di esseri humani: la Politica Criminale multilivello e la problematica distinzione con il traffico di migranti", ob. cit., passim,

15 UE, Serious and Organised Crime Threat Assesment, SOCTA, 2017, p. 53. 
situación de irregularidad para someter a los trabajadores del campo, servicios y en talleres ilegales, a las personas a condiciones de semiesclavitud ${ }^{16}$.

Conviene ahondar en las causas por las cuales estamos ante un fenómeno criminal en expansión, para poder tener claridad de análisis a la hora de establecer propuestas político-criminales y, en especial, sopesar la posible incidencia de la legislación penal en esta materia.

A nivel mundial la trata con fines de explotación sexual sigue siendo el segmento más amplio, pero en los últimos 10 años se ha incrementado la trata para trabajos forzosos, según el último Informe de UNODC. Ello hace que el perfil de la víctima ya no sea solo femenino, sino que entre las personas tratadas haya aumentado el número de hombres. Resulta significativo el dato de que "Aproximadamente cuatro de cada 10 víctimas detectadas entre 2012 y 2014 fueron traficados para trabajo forzoso, y de estas víctimas, el $63 \%$ eran hombres" ${ }^{17}$. Respecto a los niños, en 2014 representaban el 28\% de las víctimas detectadas, manteniéndose así la constante aproximada de un cuarto de los seres humanos tratados son niños. Ahora bien, aunque se ha producido un incremento de víctimas hombres, siguen siendo mayoritarias las mujeres victimizadas. Los porcentajes son: $51 \%$ mujeres adultas, $21 \%$ hombres adultos, $20 \%$ niñas y $8 \%$ niños ${ }^{18}$; por tanto, la trata de personas sigue siendo un sector de

16 En noviembre de 2015, una operación conjunta entre la policía española y la polaca, autoridades europeas, coordinada por Europol, desmanteló el funcionamiento de una red de contrabando de migrantes irregulares explotados prevenientes de Pakistán, en restaurantes de España. Los migrantes irregulares se vieron obligados a trabajar largas horas, en condiciones de trabajo totalmente ilegales, sin salario, vacaciones o seguridad para poder pagar sus deudas a los contrabandistas, consistentes en viajes y prestación de servicios de documentos fraudulentos. Con ese dinero el delincuente procedía a invertir en nuevos restaurantes, en los que volvían a utilizar la explotación de migrantes irregulares. Un negocio ciertamente redondo, en el que prácticamente el segmento de ganancias es total. Cfr. Ob. ult. cit.

17 UNODC, Global Repport on traffiching in persons, p. 6.

18 Ob. ult. cit., p. 11. 
la criminalidad en el que las víctimas suelen ser mujeres, pues llegan al $71 \%$, pese al aumento significativo de los últimos años de víctimas hombres gracias al incremento del trabajo forzoso.

Como recuerda CASTELLS, la clave del éxito y la expansión del crimen global en los años noventa es la flexibilidad y versatilidad de su organización. La interconexión es su forma de operación, tanto interna, en cada organización criminal, como en relación con otras organizaciones criminales. Las redes de distribución funcionan mediante bandas locales autónomas, a las que suministran bienes y servicios. Poseen su aparato de seguridad, pero lo más preocupante es "la red de agentes de la ley, jueces y políticos que están en su nómina"19. Y en esto es importante llamar la atención: la existencia de estas redes de la criminalidad organizada, así como la que se dedica a la trata de personas, depende en gran medida de la intervención de nacionales, profesionales, normalmente autoridades que colaboran con las organizaciones criminales ${ }^{20}$. Por esta connivencia de autoridades y profesionales con comportamientos ilícitos propios de la criminalidad organizada se refuerza con los análisis sobre los perfiles de los autores de este fenómeno criminal ${ }^{21}$. Por tanto, detrás del fenómeno de la trata de seres humanos,

19 CASTELLS, La era de la información. Fin de milenio, ob. cit., p. 213.

20 En Palma de Mallorca, en el año 2016 se detuvo a una red de policías y autoridades que extorsionaban a empresarios y trabajadoras de clubs de alterne, a los que acudían gratis, a cambio de no realizar inspecciones y archivar denuncias https://politica.elpais.com/politica/2016/07/03/actualidad/1467539442_889012.html

Esta trama policial corrupta (se llegó a investigar a 28 policías), implicaría incluso al presidente del PP de Palma, al Comisario de Palma, y a uno de los llamados empresarios de la noche. Por estos hechos también fue detenido el presidente de la Asociación de Comerciantes y Servicios Turísticos de Mallorca en mayo de 2017. http://www.diariodemallorca.es/ mallorca/2017/05/12/presidente-acotur-ingresa-prision-acusado/1214422. html Luego fue puesto en libertad en junio de 2017.

21 Un estudio sobre los perfiles criminales en la delincuencia organizada española, señala que casi un $60 \%$ de los sujetos imputados por delitos de la criminalidad organizada mantienen su actividad legal en paralelo a su actividad delictiva. Esto nos muestra que el mundo del crimen organizado no sólo 
también encontramos delincuentes de cuello blanco, con toda la particular problemática que ello plantea. En muchos casos la trata se produce dentro de negocios lícitos (bares, restaurantes, clubs de alterne, etc.), lo cual dificulta aún más su persecución penal. Además, como dato interesante, la presencia de la mujer en el delito de trata es relevante. Los estudios sobre perfiles indican que: "En cuanto al mercado de trata con fines de explotación sexual, la mujer está ampliamente representada porque el bien con el que se trafica es la mujer y constituye una actividad donde la función de la mujer es especialmente útil en diversas funciones internas de la organización" 22 . Las mujeres suelen ser captadoras y también quienes se dedican al cuidado de las mujeres tratadas.

Por supuesto que es muy difícil dar cifras ciertas sobre la trata de seres humanos, porque es un fenómeno invisibilizado, que se esconde detrás de prácticas aceptadas socialmente como la prostitución o el proxenetismo, sin embargo puede contarse con estimaciones. En 2015 el Secretario General de Naciones Unidas estimaba que 2,5 millones de personas "se encuentran atrapadas en las redes de la esclavitud moderna"23. Así, resulta verosímil el aumento de este fenómeno en una sociedad globalizada mercantilizada, donde las leyes del mercado parecen

está compuesto por profesionales del delito, sino también por colaboradores de distintas profesiones que dan soporte de todo tipo a las organizaciones criminales. Esta información resulta relevante para inducir cuántas personas se encuentran en la periferia de las organizaciones criminales, pero son las que les alimentan, le dan fuelle. Un dato, por otro lado, preocupante porque denota la complicidad de la denominada "delincuencia de cuello blanco", de personas bien situadas social y económicamente, que proporcionan soporte institucional y también lucran de la actividad ilícita, en este caso de la explotación sexual. Cfr. GIMÉNEZ-SALINAS / REQUENA / DE LA CORTE, “¿Existe un perfil de delincuente organizado?, en Revista electrónica de Derecho Penal y Criminología, No 13, 2011, p. 28, en http://criminet.ugr.es/ recpc

22 Ob. ult. cit., p. 15.

23 http://www.eldiario.es/norte/euskadi/personas-explotacion-sexual-extendida normalizada_0_414358873.html revisado 06.09.17 
marcar las reglas sociales y, por tanto, la cosificación de las personas puede resultar normalizada ${ }^{24}$.

\section{La trata de seres humanos en España}

Como sostienen DE LA CORTE IBÁÑEZ / GIMÉNEZSALINAS FRAMIS, "España se ha consolidado en las últimas décadas como lugar de almacenamiento y distribución de cocaína y el hachís para toda Europa, zona de tránsito para la inmigración clandestina procedente de países cercanos y remotos, para la ruta africana del robo de vehículos, refugio de poderosos criminales extranjeros, zona propicia a asaltos sistemáticos, operaciones de blanqueo de dinero y prácticas de explotación sexual y laboral" ${ }^{25}$. En suma, en España la trata de seres humanos, como en otros países, se expresa de manera cruda aprovechando muchas veces las rutas de los diversos tráficos ilícitos que se han facilitado gracias a la globalización. La situación geográfica de punto de intersección entre América Latina y Europa, además de puerta entrada desde África hacia Europa, el clima que propicia la exaltación de los sentidos, la economía muy volcada hacia el turismo y, por tanto, al sector servicios (bares, clubs nocturnos, lugares de alterne, etc.), son elementos para entender la relevancia de los diversos comercios ilícitos y, con especial incidencia de la trata de seres humanos en nuestro país, especialmente la relacionada a la explotación sexual.

Por supuesto que no se puede identificar prostitución con trata de seres humanos porque en el primer caso se entiende que es un intercambio voluntario mientras que en el segundo caso estamos ante comportamientos forzados, pero a nadie escapa

24 Médicos del Mundo denunciaba en 2015 que la trata de personas con fines de explotación sexual, es "una de las formas de trata más extendidas, y, desgraciadamente, más normalizada". http://www.eldiario.es/norte/euskadi/ personas-explotacion-sexual-extendida-normalizada_0_414358873.html revisado 06-09.17.

25 DE LA CORTE IBÁÑEZ / JIMÉNEZ-SALINAS, Crimen.org: evolución y claves de la delincuencia organizada, Ariel, 2010, pág. 368. 
que detrás de las bambalinas del negocio del sexo, se encuentran muchas situaciones de explotación sexual no declaradas, invisibilizadas u olvidadas. Especialmente la explotación de la prostitución ajena presenta en la realidad supuestos de forzar algunos comportamientos no queridos, de abuso, como lo demuestran diversos testimonios de mujeres tratadas y de los especialistas que se han acercado al fenómeno de la trata ${ }^{26}$. Como en el ejemplo que ponía al principio, en el negocio de la producción de pornografía no siempre es posible identificar si las conductas son realmente voluntarias o forzadas, o dónde está el límite de la explotación.

Según datos del UNODC, se calcula que en España ejercen la prostitución un número cercano a las 350.000 mujeres de las cuales el $80 \%$ son extranjeras en situación de migración irregular provenientes de Brasil, Colombia, Nigeria, Rumania, Rusia y Ucrania ${ }^{27}$. Llama la atención que el porcentaje de personas que ejercen la prostitución sean extranjeras, lo cual muestra que, en todo caso, no es un servicio muy querido por las nacionales, abocándose a ello mujeres que provienen de los países más pobres.

Por otro lado, otro dato relevante para entender la explotación sexual en España es que nuestro país es el primer país de Europa de demanda de prostitución ${ }^{28}$ y tercero a nivel mundial. Sin duda que el turismo como fuente de ingresos del país también puede esconder un turismo sexual relevante, del que hace tiempo los analistas llaman la atención ${ }^{29}$. Nuevamente hay que

26 Vid. especialmente infra epígrafe 4.4.

27 UNODC, Global Repport on traffiching in persons, p. 6.

28 https://politica.elpais.com/politica/2017/04/14/actualidad/1492199711_517599. $\mathrm{html}$

29 DE LA CUESTA ARAZAMENDI, "Las nuevas corrientes internacionales en materia de persecución de delitos sexuales a la luz de los documentos de organismos internacionales y europeos", en DIEZ RIPOLLÉS, Delitos contra la libertad sexual, Estudios de Derecho Judicial, Madrid, 1999, publicado en la red: http://www.ehu.eus/documents/1736829/2010409/CLC+ 45+Las+nuevas+corrientes+internacionales+materia+persecucion.pdf 
decir que, por supuesto, existirá una oferta de turismo sexual no ilegal, voluntario y consentido, de adultos, pero también es evidente que detrás coexisten muchas formas de trata de seres humanos, dado que la oferta de dichos servicios la realizan muy mayoritariamente mujeres extranjeras y muchas inmigrantes en situación irregular ${ }^{30}$, siendo éstas aún más vulnerables de ser presas de la mercantilización de su cuerpo. Como explica Beatriz Sánchez, la fiscal que en 2012 logró obtener las pruebas para condenar al capo rumano Ioan Clamparu, Cabeza de Cerdo, considerado como el mayor proxeneta de trata de Europa ${ }^{31}$, al que le condenaron a 30 años de prisión: "Es absurdo pensar que es libre una mujer que trabaja 24 horas y al cabo de un año no tiene cuenta, ni dinero, ni propiedades, ni paga el alquiler del piso en el que vive, ni puede rechazar un cliente" ${ }^{\prime 32}$.

30 Un informe de la Fundación Surt indica que de las 1.428 víctimas de tráfico de personas en España, el 98,7\% son mujeres. La mayoría de ellas son menores de 25 años y han sido captadas a partir de una "relación afectiva" con el explotador y con la colaboración de su familia. De las mismas, el 34\% serían rumanas. http://www.eldiario.es/catalunya/victimas-explotacion-Espanaorigen-rumano_0_541396538.html revisado 06.09.17

31 El caso de este rumano resulta clamoroso. Está considerado el responsable de la red de tráfico de mujeres que, entre 2000 y 2004, obligó a ejercer la prostitución a más de cien chicas de su país en España, aunque podrían ser muchas más. El «modus operandi» era casi siempre el mismo, casi de manual: en Rumanía, captaban a las víctimas ofreciéndoles trabajos normales en España y, una vez aquí, las obligaban a hacer la calle como esclavas, con la «excusa» de que debían abonar la deuda contraída con la organización. Aunque el destino era España, también tenía contactos en otros países como Italia, Irlanda, Francia y Reino Unido. Estaba condenado en Rumania y se encontraba refugiado en España. Una mujer tuvo el coraje de denunciarlo, pese a que cuando ella huyó envió a la casa familiar en Rumania a esbirros para amenazarlos. Los métodos para amenazar a las mujeres eran aterradores, entre ellos mostrarle unas imágenes de una mujer atada a una palmera y devorada por perros. http:/www.elmundo.es/elmundo/2012/02/01/madrid/1328126395.html revisado 01.09.17.

32 El País, "5.660 víctimas de esclavitud afloran tras las reformas de los últimos años". Reportaje del 17 de abril de 2017, https://politica.elpais.com/ politica/2017/04/14/actualidad/1492152357_266303.html?rel=mas revisado 28.09.17. 
Ciertamente que muchas mujeres vienen a España con conocimiento y voluntad de ejercer la prostitución porque en su país de origen no hay otra alternativa a la supervivencia, pero eso no impide que en algunos casos se produzcan engaños sobrevenidos o situaciones de explotación. Según Médicos del Mundo, España "es país de tránsito y destino de mujeres y niñas víctimas de trata". Su presidenta, Yolanda Rodríguez, advierte de que "las condiciones en las que estas mujeres se ven obligadas a ejercer la prostitución, y las consecuencias que para su salud física y psíquica tiene este ejercicio atentan contra los derechos fundamentales de las personas: el derecho a la vida, el derecho a la libertad, a la integridad física y moral, a la libertad sexual, a la salud, a la intimidad y a la dignidad humana"33.

Como no podemos contar con datos ciertos sobre la trata de seres humanos, corresponde inducirlo de indicios, de ahí que todos estos análisis, reportajes periodísticos, estudios, noticias, obligan a reconocer que el problema de la trata en España es una cuestión seria en cuanto a cifras y en cuanto a profundidad. La invisibilidad que caracteriza este fenómeno criminal, redunda en la necesidad de acudir a todas las fuentes posibles para comprender la incidencia de la trata en nuestro país ${ }^{34}$.

\section{Dificultades para un planteamiento de Política Criminal contra la trata de seres humanos}

Como se ha podido ver hasta ahora, nos encontramos con un fenómeno criminal con escasa visibilidad por parte de la Sociedad, la cual parece no reconocer en muchas ocasiones las

33 http://www.eldiario.es/norte/euskadi/personas-explotacion-sexual-extendida normalizada_0_414358873.html revisado 06.09.17.

34 Mientras la Fiscalía de Extranjería detalla cada año en sus informes la detección de entre 1.300 y 1.400 víctimas de trata, el Plan contra la Trata del Ministerio de Sanidad estima que estas mujeres son un tercio de todas las que ejercen la prostitución, 40.000 según sus estimaciones. "Las cifras de la explotación sexual en España: 40.000 mujeres la sufren”, http://ecodiario. eleconomista.es/sociedad/noticias/7845621/09/16/Las-cifras-de-la-explotacion-sexual-en-Espana-40000-mujeres-la-sufren-.html revisado 06.09.17 
dimensiones del daño, del dolor infligido a sus seres más vulnerables, mayormente pobres, mujeres y niños. Las estadísticas escasean o están hechas por diversos organismos con diferentes resultados ${ }^{35}$ y las condenas por estos crímenes tampoco abun$\mathrm{dan}^{36}$, por todo lo cual es fácil vislumbrar que existe una gran cifra negra de la criminalidad en este ámbito. Como ha denunciado el Informe presentado a la OEA la ONG Women's Link WorldWide, la indiferencia es lo que más golpea a las víctimas de trata en América Latina. Las víctimas están desprotegidas en ese Continente, pues no existen planes de protección, apoyo social y también escasean las condenas. Además, el enfoque punitivo, muchas veces, revictimiza a las víctimas al dejarlas a merced de sus captores cuando denuncian los hechos ${ }^{37}$. Obviamente, este en fenómeno como el de la violencia de género, en

35 Así por ejemplo, el Informe presentado a la OEA por Women's Link Worldwide en mayo de 2017, revela que ninguno de los cinco países estudiados (Colombia, Ecuador, México, Paraguay y Perú) cuenta con datos unificados ni fiables, que permitan dimensionar la magnitud y las dinámicas de este delito. Cfr. Documento: WOMEN'S LINK WORLDWIDE, Victimas de trata en América Latina. Entre la desprotección y la indiferencia, 2017, pp. 22 y 23, en la red: https://www.womenslinkworldwide.org/

36 Realmente las cifras de condenas por este delito son irrisorias frente a las cifras que muestran la realidad de las noticias y los estudios sobre el tema. Según denuncian Women's Link Worldwide en Colombia, las autoridades no tienen un protocolo para la identificación de posibles casos. De enero de 2011 a abril de 2016, solo hubo 52 sentencias condenatorias de 908 investigaciones. En Ecuador se produjeron 26 sentencias de 742 denuncias. Apenas se identifican, lo que impide la protección de los derechos de las víctimas. México, con 152 sentencias, es el único de los países que se considera "proactivo" a la hora de detectar situaciones de trata interna. En Paraguay, entre 2010 y 2013, el Ministerio Público reportó 145 investigaciones por este delito y hubo 19 condenas. Allí tampoco se ha reparado a las víctimas. En Perú, para ser reconocidas deben interponer una acción legal. De 908 procesos entre 2011 y 2016, solo hay 52 sentencias. Cfr. "La indiferencia golpea a las víctimas de trata en América Latina”. En España recién se encuentran sentencias a partir de 2015 sobre el tipo penal de trata porque se introdujo en 2010 y aún son pocas, de acuerdo a la consideración del país como país de tránsito y destino de trata.

37 Una menor venezolana de 13 años vendida por su padre para un burdel de una ciudad fronteriza de Colombia, fue devuelta a Venezuela pese a los temores 
que no se puede castigar al autor de los hechos si antes no se prevé cómo proteger a la víctima, pues de lo contrario el autor tarde o temprano volverá contra ella.

Ahora bien, para programar una Política Criminal capaz de hacer frente a la trata de seres humanos en cuanto a prevención y represión es preciso tener claridad de objetivos, algo que no es fácil en este fenómeno criminal que se esconde tras varias contradicciones, intereses contrapuestos, realidades complejas, ambigüedades. La ley penal que se plasma en tipos penales que realizan una serie de generalizaciones sobre las conductas punibles, no permite captar algunas particularidades que pueden presentarse en la realidad. Se observan una serie de presunciones que son hechas desde el púlpito de los Congresos, olvidando muchas veces las sensibilidades personales que pueden acaecer detrás de este fenómeno. Mi objetivo es poner en evidencia estas contradicciones para afinar una protección penal de los derechos humanos de los más débiles.

\subsection{Trata de seres humanos y tráfico de personas}

Uno de los principales problemas que ha tenido la persecución penal de la trata de seres humanos, especialmente en Europa, es la mimetización de los fenómenos de trata y tráfico de personas. Ciertamente que en muchos casos son fenómenos coincidentes, en la medida que los migrantes irregulares se convierten en sujetos vulnerables víctimas de la trata de seres humanos, pero en realidad son fenómenos muy diferentes que requieren un tratamiento político-criminal inclusive muchas veces contrapuesto. Sin entrar en detalles sobre las diferencias, principalmente ha de recordarse que mientras la trata es un fenómeno coactivo, en el que no existe voluntariedad ya sea porque hay violencia, engaño o abuso de situación de necesidad o vulnerabilidad, en el tráfico de personas el migrante realiza el

de la víctima, amenazada de muerte por su padre. Vid. "La indiferencia golpea a las víctimas de trata de América Latina", https:/elpais.com/internacional/2017/05/23/colombia/1495512913_588284.html, revisado 28.09.17. 
tránsito voluntariamente porque es su aspiración vivir en otro país. Además, esta identificación olvida el fenómeno de la trata interna, importante en algunos países donde los desplazamientos son desde zonas pobres a zonas ricas o enclaves concretos, como sucede con la minería ilegal en Perú, Brasil o Ecuador. El último Informe de UNODC sobre la trata de seres humanos indica que el $42 \%$ de las víctimas son objeto de trata interna, una cifra ciertamente importante ${ }^{38}$.

Efectivamente, tal como pone en evidencia PÉREZ ALONSO, la política europea de trata de seres humanos se ha centrado hasta hace muy poco en un paradigma migratorio y criminocéntrico, olvidando los deberes de protección de los Estados con las víctimas. Recién con el Convenio del Consejo de Europa sobre lucha contra la trata de seres humanos firmado en Varsovia en 2005, se promueve un cambio de paradigma orientado hacia la protección de las víctimas, o perspectiva victimocéntrica. Esta orientación político-criminal hacia el reconocimiento de los derechos humanos de las víctimas se ha hecho patente en la última Directiva 2011/36/UE sobre prevención y lucha contra la trata de seres humanos. El autor pone en evidencia como desde el Protocolo de Palermo de 2000, se ha promocionado las llamadas tres Ps: prevención, persecución y protección de las víctimas, propiciando políticas criminales idóneas para proteger los derechos humanos de las víctimas de trata ${ }^{39}$.

En España los especialistas han denunciado el enfoque trafiquista de la de trata de seres humanos y sus inherentes contradicciones, dejando en clara desprotección a las víctimas ${ }^{40}$. Esto es, privilegiando intereses de la UE por controlar la inmigración irregular con el instrumento penal, los países europeos

38 UNODC, Global Repport on traffiching in persons, 2016, p. 9.

39 PÉREZ ALONSO, "La Política Criminal europea en materia de trata de seres humanos", Revista de la Facultad de Derecho de la Universidad de Granada, No 16-17, 2013-2014, pp. 1147 y ss.

40 Vid. por todos DAUNIS RODRÍGUEZ, La trata de seres humanos, Valencia, Tirant lo Blanch, 2013, pp. 32 y ss. 
y principalmente los países del sur de Europa más amenazados por la inmigración, han promulgado una serie de leyes penales que prácticamente desprotegían a las víctimas de trata, al no poder denunciar por ser inmediatamente procesadas como inmigrante irregular, por delitos de tráfico de personas o inmigración clandestina. En nuestra legislación hasta el año 2010 se dispensaba una protección común a la trata y al tráfico de personas, con el art. 318 bis CP, introducido en el año 2000 bajo la rúbrica de "Los delitos contra los ciudadanos extranjeros". Como sostiene VILLACAMPA, "con ello el Estado español mostraba una aproximación al fenómeno de la trata apegada a los orígenes, en que dicha realidad se relacionaba con la de la inmigración clandestina, vinculada con la política de la Unión de la Europa fortaleza, de la estratificación de la ciudadanía y de la apartheid de la misma. Con la anterior regulación en nuestro país se desoía la tendencia cada vez más asentada internacionalmente a deslindar, como realidades diferenciadas, el control de fronteras y los límites jurídicos a la residencia legal de los foráneos -con la relevancia penal que tales conductas, en su caso, puedan entrañar- de una realidad mucho más sangrante, la del traslado de personas al primer mundo y su trato durante el tránsito y una vez en él cual si fueren cosas para ser explotadas" ${ }^{41}$. Ciertamente la Europa de la seguridad y las libertades era concebida para sus ciudadanos, mientras que "los otros", los inmigrantes, tendrían otros derechos, pero no plena ciudadanía. Dentro de este marco las víctimas de trata de seres humanos se presentan como sujetos indefensos, carentes de protección, lo cual puede aumentar aún más su grado de vulnerabilidad frente a las organizaciones criminales que buscan con ánimo de lucro el comercio de personas. Tal como apunta DAUNIS, "el control estatal de la inmigración es precisamente el que aboca al inmigrante a la vulnerabilidad y/o victimización. Incluso, se constata como se utiliza, de forma perversa, la protección o salvaguarda del inmigrante para, en

41 VILLACAMPA ESTIARTE, “art. 177 bis”, QUINTERO OLIVARES (Dir.), Comentarios al Código Penal español, Navarra, Aranzadi, 2011, T. I, p. 1099. 
realidad, establecer más controles u obstáculos a la inmigración, generando una mayor situación de desprotección jurídica o vulnerabilidad en el inmigrante ${ }^{42}$.

Este enfoque desde la lucha contra la inmigración ilegal y de índole criminógeno primordialmente ha coadyuvado también a que so pretexto de luchar contra las mafias o la criminalidad organizada que lucra con el tráfico de personas, lo que realmente se escondía son los intereses de los Estados por controlar los flujos migratorios desde los países con problemas humanitarios por guerras, hambre, desastres naturales, hacia Europa. Quedaba claro pues, que tras la protección de los ciudadanos extranjeros por parte del art. 318 bis $\mathrm{CP}$, de lo que realmente se trataba es de la protección de la política migratoria del Estado español, que son bienes jurídicos totalmente distintos. La utilización de los términos "mafias" por parte de los políticos y de la prensa y las referencias entre inmigración y criminalidad organizada posee otro efecto contraproducente: asimilar todo traslado de migrantes a conductas coactivas próximas a la esclavitud, algo que en muchos casos no es lógicamente así.

Así se observan las contradicciones entre dos fenómenos próximos aunque diferentes: trata de seres humanos (trafficking in person) y tráfico de personas (smugling of migrants). Las simplificaciones vinculando inmigración ilegal con delincuencia organizada tienen como efecto, además, dos consecuencias para el abordaje ulterior de la trata de seres humanos y la prostitución: la generalización de la situación de vulnerabilidad del migrante y la consideración de que todas las personas (especialmente, las mujeres migrantes) que ejercen la prostitución son (o han sido) víctimas de trata de seres humanos ${ }^{43}$.

42 Cfr. DAUNIS RODRÍGUEZ, "La inmigración ante la encrucijada: el tráfico de personas, la trata de seres humanos y la explotación sexual”, en ZÚÑIGA RODRÍGUEZ (Dir.), Criminalidad organizada transnacional: una amenaza a los Estados democráticos, Valencia, Tirant lo Blanch, 2017, p.

43 Ob. ult. cit., p. 457. 
Ahora bien, felizmente en los últimos años esta situación ha ido cambiando, especialmente desde la incorporación en el CP del delito de trata de seres humanos en el año 2010 y, más aún, con la Directiva 2011/36/UE en que desde los ámbitos internacionales europeos se propicia un tratamiento diferenciado del tráfico y la trata de seres humanos potenciando la protección de los derechos humanos de las víctimas. La autonomía conceptual y normativa de la trata de seres humanos frente a la política migratoria de los Estados y frente a la lucha contra la criminalidad organizada, ha sido un asunto clave para llevar a cabo una real Política Criminal que proteja a las víctimas del comercio sexual o laboral a que pueden ser sometidas ${ }^{44}$.

\subsection{Prostitución y trata de seres humanos con fines de explotación sexual}

Otro de los aspectos en que pueden darse planteamientos contradictorios o intereses contrapuestos es respecto a la regulación que los países tengan o proyecten respecto al tratamiento de la prostitución y la prevención y persecución de la trata de seres humanos. Como sostiene LORENTE-MOLINA, "la prostitución es un fenómeno multidimensional que requiere de aproximaciones complejas" ${ }^{\prime 4}$. Por tanto las regulaciones suelen plantear discusiones importantes, ya que la visión desde que se parte sobre el fenómeno o la orientación que se pretende dar en las propuestas legislativas, pueden ser muy distintas y hasta polémicas. Sin entrar en los diversos modelos y haciendo hincapié en que en pleno siglo XXI no hay acuerdos ni siquiera en Europa, basta señalar las dos posiciones contrapuestas existentes dentro del propio feminismo: el abolicionismo y el modelo laboral. Ciertamente

44 Como sostiene MILITELLO, "La tratta di esseri humani: la Politica Criminale multilivello e la problematica distinzione con il traffico di migranti", ob. cit., p. 94: una aproximación holística de la trata atiende no sólo a la represión sino también a la prevención del fenómeno como los derechos de las víctimas, afirmados a nivel supranacional".

45 LORENTE-MOLINA, Belén, "Otredad, marginación y política en la prostitución", en LAURENZO COPELLO / DAUNIS RODRIGUEZ, Colectivos en los márgenes del Derecho, Valencia, Tirant lo Blanch, 2016, p. 305. 
que las visiones de ambas posturas acerca de la prostitución son contrapuestas. Para el feminismo radical que postula el abolicionismo, la prostitución es una actividad propia de la violencia de género del patriarcado, degradante, que cosifica a la mujer (quien es la que principalmente la ejerce) y, por tanto, ha de erradicarse persiguiendo principalmente al cliente ${ }^{46}$. Para esta posición, la prostitución y la explotación de la prostitución ajena son muy cercanas a la trata, en la medida que la voluntariedad estaría alterada por las condiciones socioeconómicas de desigualdad que caracterizan la prostitución. Desde luego, desde esta postura el tratamiento de la trata y la prostitución es similar y toda forma de explotación sexual es prohibicionista por atentar contra la dignidad de la mujer ${ }^{47}$.

Por el contrario, las especialistas que son partidarias del modelo laboral, es decir, de considerar el ejercicio de la prostitución voluntaria como un trabajo sexual ${ }^{48}$, con derechos sociales

46 Principal referente de este modelo es la Ley sueca que castiga al cliente de la prostitución desde 1999. Tras Suecia, la criminalización de los clientes de la prostitución se ha aprobado en Islandia, Canadá, Singapur, Sudáfrica, Corea del Sur, Irlanda del Norte (desde 2015) y Francia (2016). Cfr. El Pais, "Prohibido pagar por sexo en Suecia, Francia y otros seis países, 21 de abril de 2016, https:/elpais.com/internacional/2016/04/07/actualidad/1460050306 463588.html revisado 20.09.17

47 Como apunta BOZA MORENO, Elena, Sobre la prostitución. Un análisis desde la política criminal y su necesidad de legalización, Tesis Doctoral, Universidad Pablo de Olavide, 2017, p. 74, respecto a la Directiva $\mathrm{N}^{\circ}$ 2011/36/UE relativa a la prevención y lucha contra la trata de seres humanos y la protección de las víctimas: "la política seguida en los textos europeos es de corte abolicionista. De este modo, se reconoce que la prostitución y la explotación sexual son cuestiones de género y que contribuyen a la violación de la dignidad humana, siendo estas contrarias a los principios de los derechos humanos, como la igualdad de género, y por consiguiente contrarias a la Carta de los Derechos Fundamentales de la Unión Europea".

48 Vid. por todas JULIANO, María Dolores, "Transformaciones de la prostitución y del trabajo sexual en la era de la industria del sexo", en IGLESIAS SKULJ / PUENTE ABA, Sistema penal y perspectiva de género: trabajo sexual y trata de personas, Valencia, Tirant lo Blanch, 2012, p. 158: “... cuando hablamos de trabajo sexual nos referimos al altísimo porcentaje de mujeres y hombres que se dedican a esta actividad por las mismas razones que cada un@de nosotr@s nos dedicamos a cualquier otra actividad”. 
y laborales, que es potenciado por otro sector del feminismo ${ }^{49}$, consideran que el abolicionismo en lugar de proteger a la mujer que ejerce la prostitución, más bien la conmina a ejercer los servicios sexuales en malas condiciones, aumentando aún más su vulnerabilidad frente a los clientes, corriendo más riesgos en una actividad que de por sí suele rodearse de clandestinidad. Ciertamente desde planteamientos victimológicos es asumido que el prohibicionismo no resuelve los problemas, sino los esconde y, en algunos casos los agranda, como puede suceder con actividades que de por sí suelen estar rodeadas de cierta violencia como la prostitución. Por tanto, el abolicionismo lejos de proteger a las mujeres que ejercen a la prostitución, las deja a merced del cliente, del proxeneta o de las organizaciones criminales.

Cierto es que todo prohibicionismo de la prostitución (incluso el neoabolicionismo que se centra en la penalización del cliente) puede conllevar desprotección hacia las personas que ejercen la prostitución, que lejos de ayudarlas puede revictimizarlas, pero también ha de reconocerse que el modelo laboral tiene sus limitaciones. Este modelo parte de una distinción entre prostitución libre y prostitución coactiva que estaría más cercana a la trata ${ }^{50}$. Ahora bien, el problema está en que existen muchos supuestos límites donde no es fácil establecer una línea de delimitación entre prostitución libre y prostitución coactiva, especialmente en los supuestos de vulnerabilidad de la víctima, donde no hay engaño, violencia o intimidación. Es decir, la problemática empieza cuando pretendemos dar tratamiento distinto a dos realidades que muchas veces se superponen o se esconden una tras otra.

49 Ob. ult., cit.: “.... la conflictiva relación entre feminismo y prostitución... el tema del trabajo sexual genera discusiones, contradicciones y posiciones duramente encontradas en muchos casos".

50 Para más detalles sobre los modelos de criminalización de la prostitución, sus ventajas e inconvenientes Vid. VILLACAMPA, Carolina, "Análisis de las políticas de criminalización de la prostitución”, en IGLESIAS SKULJ / PUENTE ABA, Sistema penal y perspectiva de género: trabajo sexual y trata de personas, Valencia, Tirant lo Blanch, 2012, pp. 1 y ss. 


\subsection{Vulnerabilidad vs Libertad para ejercer la prostitución}

Precisamente en este punto se encuentra el quid del asunto respecto al tratamiento de la trata con fines de explotación sexual, a mi entender, el valor que han ido dando en los últimos tiempos los instrumentos internacionales a la vulnerabilidad de las víctimas de trata y cómo esto ha sido considerado más bien perjudicial para algunos sectores que propugnan la liberalización del ejercicio de la prostitución.

El énfasis en la protección de los derechos humanos de las víctimas de trata de personas proviene del Preámbulo de la Convención de Naciones Unidas contra la Criminalidad Organizada Transnacional de 2000: "En la Cumbre del Milenio los dirigentes de todo el mundo proclamaron que la liberación del temor y de la miseria era uno de los valores esenciales del siglo XXI. No obstante, en todo el mundo hay millones de personas a quienes todavía se niega el derecho a vivir con dignidad y liberados del temor y de la miseria. Se niega ese derecho al niño que trabaja bajo contrato de cumplimiento forzoso, sometido a explotación, al padre que tiene que dar soborno para conseguir atención médica para su hijo o hija, a la mujer condenada a una vida de prostitución forzosa". En el mismo Kofi Annan, Secretario General de Naciones Unidas en ese entonces, insiste: "Considero que la trata de personas, especialmente de mujeres y niños, para someterlos a trabajos forzosos y a la explotación, incluida la explotación sexual, es una de las violaciones más atroces de los derechos humanos a que hacen frente las Naciones Unidas en la actualidad. Se trata de un fenómeno muy difundido que se agrava cada vez más. Tiene sus raíces en las condiciones sociales y económicas de los países de origen de las víctimas y se ve facilitado por las prácticas discriminatorias contra la mujer e impulsado por la cruel indiferencia ante el sufrimiento humano de parte de los que explotan los servicios que las víctimas están obligadas a prestar. El destino de esas personas más vulnerables es una afrenta para la dignidad humana y un grave problema para todo Estado, todo pueblo y toda comunidad". 
Desde ese momento se despliegan una serie de normas internacionales destinadas a la protección de los derechos humanos de los más débiles ${ }^{51}$, especialmente mujeres y niños, frente a la explotación sexual o laboral de los más fuertes, mafias, padres que venden a sus hijos, etc., e insta a los Estados a protegerlos con la armonización de las leyes y la cooperación internacional. Es decir, abolida la esclavitud en las Cartas Internacionales de los Derechos Humanos en los años cincuenta, Naciones Unidas se empeña en hacer realidad la abolición de las nuevas formas que esclavizan a los seres humanos, la explotación del hombre sobre el hombre. En dicho afán, los relatores de los acuerdos internacionales se percatan que estas conductas no solo se realizan con violencias explícitas, sino en muchísimos casos existen abusos de la situación de superioridad, como sucede con padres, maestros, autoridades, o abuso de situación de vulnerabilidad, cuando los tratantes se aprovechan de la situación de pobreza, marginalidad, incapacidad para sobrevivir, etc. En estos supuestos las víctimas no tienen capacidad de elección, tampoco existe una oposición clara frente a la explotación, porque realmente no poseen opciones de vida, esto es, su libertad de autodeterminación está muy limitada. Es el caso de la trata abusiva, más observable en países o zonas donde se encuentra extrema pobreza y las niñas y niños son vendidos por sus padres o siendo mayores son echadas a la calle para que "se busquen la vida".

Sin embargo, en la doctrina algunos autores se muestran críticos con el concepto de vulnerabilidad. Así MAQUEDA ABREU, cuestionando el desarrollo que la legalidad internacional hace de la vulnerabilidad de las mujeres, sostiene: "Como siguiendo una consigna secreta, las distintas regulaciones comenzaron a abandonar paulatinamente las viejas referencias a la prostitución libre o forzada para sustituirlas por un término equívoco que aún permanece indefinido: el de explotación sexual. La

51 Vid. por todos DE LA CUESTA ARAZAMENDI, "Las nuevas corrientes internacionales en materia de persecución de delitos sexuales a la luz de los documentos de organismos internacionales y europeos", ob. cit., passim. 
trata, por su parte, acabaría identificándose como una realidad coercitiva, pero su presupuesto, el vicio del consentimiento, ya no iba a quedar limitado a las situaciones clásicas de violencia, intimidación o engaño sino que se ampliaría peligrosamente a otras circunstancias de debilidad personal o económica condicionantes de la libertad sexual de las víctimas. Fue entonces cuando hizo su aparición la noción de vulnerabilidad"52. Según esta autora, el discurso de la vulnerabilidad esconde un tratamiento de las mujeres que ejercen la prostitución de personas débiles, con capacidades limitadas para decidir por sí mismas ${ }^{53}$. Siguiendo esta misma línea de análisis, habría "una presunción de involuntariedad en relación a la práctica de la prostitución que se resiste a someterse a prueba" ${ }^{54}$.

Nuevamente nos topamos con la problemática de la voluntariedad del ejercicio de la prostitución, algo que defienden las partidarias del modelo laboral para la regulación de la prostitución. Como hemos venido señalando, para los sectores que propugnan la liberalización del ejercicio de la prostitución proponiendo regulaciones que reconozcan los derechos laborales y sociales, tal como un trabajo sexual, en los acuerdos internacionales se ha impuesto una visión abolicionista que asimila la prostitución a la trata y la explotación sexual y todos serían "males" destinados a erradicar, dejando sin contenido la prostitución libre, ejercida por mujer adulta con su pleno consentimiento.

Indudablemente existe un ejercicio de la prostitución libre, consentido, no sometido a explotación, o si esta existe es también consentida. Pero tampoco puede desconocerse la exis-

52 MAQUEDA ABREU, "Cuando el discurso sobre la vulnerabilidad se convierte en un discurso ideológico (A propósito de las "víctimas" de la prostitución y el tráfico sexual de mujeres”, en PÉREZ ÁLVAREZ (Ed.), Serta, In memoriam Louk Houlsman, Ediciones Universidad de Salamanca, 2015, p. 450 .

53 Es más, según esta autora, Ob. ult. cit., p. 452, se trata de "la mirada colonial' de las feministas occidentales orientada a perpetuar la presunción de infantilismo y desvalimiento de las mujeres del Tercer Mundo".

54 Ob. ult cit., p. 453. 
tencia de situaciones de explotación sexual, de abuso de situaciones de necesidad que son aprovechadas por tratantes que obligan a las mujeres a sometimientos insufribles. Creo que no puede presumirse que todo ejercicio de la prostitución es coactivo, pero tampoco puede presumirse que todo ejercicio de la prostitución es libre; ambas presunciones son extremistas. Como se ha venido insistiendo, existen muchos supuestos en que el ejercicio de la prostitución de adulta esconde explotación sexual cercana a la trata de seres humanos. Existen muchos claro-oscuros, y es difícil saber con datos cuántas mujeres ejercen la prostitución de manera voluntaria y no forzadas por situaciones de necesidad, que son muy distintas en países como los europeos donde existen opciones sociales de ayuda, respecto de países del África, Asia o América Latina donde las mujeres pobres no tienen otra opción de vida ${ }^{55}$.

Como apuntan MINTJAS y MOLINAR, que han elaborado un estudio sobre la victimización de las trabajadoras sexuales en la Provincia de Málaga, "A lo largo del trabajo se ha observado cómo la sexualidad, la inmigración, la identidad sexual, la creciente feminización de la pobreza y la crisis económica se van entrelazando, dando lugar a las diversas realidades que hemos podido analizar. Realidades complejas de seres humanos que no se pueden codificar en "víctima" o "no víctima"56.

55 De acuerdo a lo que se ha dicho tantas veces, en el fenómeno de la trata parece que una realidad encubre otra y otra, cual muñecas rusas. Como pone de relieve el Informe de Women's Link WorldWide respecto a cinco países de América Latina, es preciso "hacer mayores esfuerzos por detectar la trata interna y otros fines explotación, pues hay una tendencia a identificar solamente a víctimas de explotación sexual y trabajos forzados, mientras otras modalidades como la mendicidad, el matrimonio servil, la servidumbre doméstica o el tráfico de órganos son identificados excepcionalmente". WOMEN'S LINK WORLDWIDE, Victimas de trata en América Latina. Entre la desprotección y la indiferencia, 2017, Resumen ejecutivo, p. 2.

56 MINTJAS / MOLNAR, "Trabajadoras sexuales: víctimas de la exclusión. Estudio sobre la victimización de las trabajadoras sexuales en la provincia de Málaga, en LAURENZO COPELLO / DAUNIS RODRIGUEZ, Colectivos en los márgenes del Derecho, Valencia, Tirant lo Blanch, 2016, p. 366. 
Igualmente, existen muchos supuestos que no se pueden codificar binariamente en prostitución libre o prostitución coactiva, especialmente en los casos de abuso de situación de necesidad. En el mismo estudio antes mencionado, si bien se advierte que las mujeres admiten que comenzaron a ejercer la prostitución por voluntad propia, lo cierto es que "todas se ven ejerciendo otra profesión en el futuro" ${ }^{57}$. Feminización, pobreza, inmigración clandestina y marginalidad se suelen asociar en la práctica de la prostitución, donde no queda siempre clara la autonomía de la voluntad.

Como no reconocer la vulnerabilidad en la que se encuentran muchas mujeres y niños, normalmente los más golpeados por la pobreza en el mundo. Prueba de ello es que los datos sobre trata que revelan los informes internacionales inciden en que las víctimas suelen provenir de los países más pobres de la tierra $^{58}$, sin contar con la trata interna que normalmente se realiza de zonas pobres a zonas ricas dentro de los propios países. Los desequilibrios económicos y sociales de los últimos tiempos no auguran que estemos yendo por el buen camino para desactivar las situaciones que condenan a millones de personas a vivir sin dignidad, sin libertad, libre de la miseria esclavizante. El Informe sobre Desarrollo Humano de 2016 señala que, pese a los importantes avances de los últimos años para erradicar la pobreza, aún "una de cada nueve personas en el mundo padece hambre y una de cada tres malnutrición. Anualmente, alrededor de 15 millones de niñas se casan antes de los 18 años, es decir, casi una cada dos segundos. En todo el mundo mueren al día 18.000

57 Ob. ult. cit., p. 346. Igualmente en España, la mayoría de las condenas por trata de personas revelan que se trata de víctimas procedentes de países que no poseen protección social, como Rumanía, Nigeria, Marruecos, Colombia, etc., con un mismo modus operandi: les engañan en sus países de origen con trabajos en España o Europa y luego al llegar a territorio español les despojan de sus documentos y las obligan a ejercer la prostitución para pagar los gastos de su traslado (viajes, pasaporte, permisos, etc.). Estos son supuestos de una clara situación de abuso de la vulnerabilidad. Incluso algunas sentencias lo definen expresamente.

58 Vid. nota 12. 
personas debido a la contaminación atmosférica, y el VIH infecta a 2 millones de personas al año. En promedio, 24 personas por minuto se ven desplazadas forzosamente de sus hogares. Estas carencias básicas son comunes entre diversos grupos. Las mujeres y las niñas, las minorías étnicas, los pueblos indígenas, las personas con discapacidad y los migrantes se ven privados de las dimensiones básicas del desarrollo ${ }^{59}$."

Las personas que se encuentran en situación de extrema pobreza, sin perspectivas de apoyo social ni familiar obviamente que son vulnerables y posibles presas de personas u organizaciones criminales que se aprovechan de esa situación para explotarlas. Y que el peso de la ley penal ha de caer sobre los victimarios para proteger a dichas víctimas, no creo que sea discutible. Ahora bien, ciertamente que hay contextos sociales en que se desarrollan prácticas, incluso en situaciones de extrema pobreza donde resulta complejo establecer una diferencia nítida entre víctimas y victimarios, consentimiento o coacción, esto es, realidades binarias. Como el estudio de campo de MUJICA en Perú, sobre la explotación sexual en una zona de la Amazonia, caracterizada por industrias extractivas de madera, petróleo, minerales y gas, que muestra resultados sorprendentes. El ciclo de la explotación (sexual, laboral), se inscribe dentro de una práctica cotidiana de la lógica organizacional de la comunidad, vinculada a la distribución por sexo y edad, asociada la violencia estructural, caracterizada por la precariedad, la pobreza y la desigualdad. Dentro de ese ciclo, las niñas a partir de los 12 años son empleadas en los bares en los que también se ofrecen servicios sexuales y salen de esa actividad entre los 19 y 25 años cuando tienen su segundo hijo, en el que suelen poner un pequeño puesto de ventas. Ellas perpetúan este ciclo empezando por la recolección de madera de los niños pequeños y a los 12 años envían a sus hijas a hacer el mismo trabajo que ellas hicieron. Vemos como no es difícil pensar que las explotadas-víctimas se

59 PROGRAMA DE LAS NACIONES UNIDAS PARA EL DESARROLLO (PNUD), Informe sobre Desarrollo Humano 2016, p. 5. 
convierten en victimarias-tratantes y que estas prácticas no se realizan desde el crimen organizado, sino en la cotidianeidad del ciclo vital de la supervivencia ${ }^{60}$.

Seguramente este ejemplo podría ser trasladable a otras zonas de Asia o África, de donde provienen las mujeres tratadas a nuestros países europeos. Por eso se entiende como situación de vulnerabilidad, según la ley "cuando la persona no tiene otra opción que dedicarse a la prostitución" y ello se ha entendido así cuando las mujeres son traídas de sus países de origen con falsas promesas, como inmigrantes irregulares tienen pocas o ninguna opción de salir del círculo de sus captores. También cuando de inicio se plantean unas condiciones y luego se convierten en más gravosas.

Desde el punto de vista criminológico siempre en la trata hay una realidad asimétrica entre tratante y víctima. Como argumenta MONTOYA, "la explotación efectiva de una persona - la explotación de la prostitución ajena, la explotación sexual, la servidumbre, el trabajo forzado, la esclavitud, etcétera- configura también una situación de dominio de una persona sobre otra, pero esta forma de dominio resulta una expresión cuantitativamente más intensa que aquel dominio inicial expresado en el uso de la violencia, la amenaza, el engaño o el abuso de una situación vulnerable con fines de explotación" ${ }^{\prime 1}$. Lo que pretende resaltar el autor es que más allá de los medios iniciales para hacer entrar a la víctima en la lógica del tratante, lo realmente grave es ese dominio permanente que ejerce el victimario, ins-

60 MUJICA, Jaris, "Trayectorias y ciclos de explotación sexual y trata para la explotación sexual de mujeres en la Amazonía peruana", en ANTHROPOLOGICA, Año XXXII, N. ${ }^{\circ} 33,2014$, pp. 163-177. También MUJICA, Jaris y CAVAGNOUD, Robin, "Mecanismos de explotación sexual de niñas y adolescentes en los alrededores del puerto fluvial de Pucallpa", en ANTHROPOLOGICA, Año XXIX, № 29, diciembre de 2011, pp. 91-110.

61 MONTOYA VIVANCO, Yván, "El delito de trata de personas como delito complejo y sus dificultades en la jurisprudencia peruana, en ZÚÑIGA RODRÍGUEZ (Dir.), Criminalidad organizada transnacional: una amenaza a los Estados democráticos, Valencia, Tirant lo Blanch, 2017, p. 491. 
trumentalizando a la persona para sus fines propios, el cosificar a la persona, en degradar la autonomía de su voluntad a cero.

Lo deleznable es que se aproveche el discurso de la vulnerabilidad para perseguir todo ejercicio de la prostitución y especialmente a las inmigrantes irregulares, algo que ha sido denunciado por todos los ámbitos. Las simplificaciones, reduccionismos, generalizaciones en este campo tan espinoso de diferenciar prostitución, trata e inmigración, han de ser erradicadas, entre otras razones porque si no se tiene claridad de conceptos, difícilmente los van a tener los agentes del orden para perseguir a los victimarios y proteger a las verdaderas víctimas.

\subsection{Explotación sexual libre o coactiva}

El tratamiento penal de las personas que viven de la explotación de la prostitución ajena también ha resultado en la política criminal un asunto complicado. Los sectores más liberales han sido muy críticos con la criminalización del proxenetismo cuando este se realiza con mujeres adultas con consentimiento. Sin embargo, desde la lucha contra la trata de personas con fines de explotación sexual se postula que para poder hacer frente con eficacia a esta lacra que afecta principalmente a mujeres y niños, es preciso perseguir toda forma de explotación sexual, seguramente en la creencia que detrás de ella se esconden abusos, situaciones humillantes, cercanas a la trata. Ciertamente que esta última postura parece desconocer la libertad de la mujer trabajadora sexual mayor de edad que en su capacidad de autodeterminación decide ofrecer a su pareja, amigo o quien quiera, los beneficios obtenidos por sus servicios.

Sin duda la postura sobre la respuesta penal frente al proxenetismo está vinculada a la visión que se tenga sobre la prostitución y al modelo que se proyecte para regularla. Como se ha dicho, desde el modelo abolicionista prostitución, trata y explotación sexual son males a erradicar porque constituyen formas de violencia contra la mujer, que las degrada como personas y, no existiría espacio para la prostitución libremente elegida, por lo cual el proxenetismo debe también castigarse. En cambio, 
para aquellos que plantean el modelo laboral y el reconocimiento de la prostitución libre, castigar el proxenetismo es una forma de estigmatizar al tercero que se lucra con una actividad que debe ser reconocida con todos sus derechos.

Nuevamente la discusión se centra en la explotación sexual abusiva, esto es, en la que no media engaño, ni violencia, ni intimidación, pues en estos casos clara está su reprochabilidad, sino cuando se debe a un abuso de situación de necesidad. Los convenios internacionales parecen ir por el camino más cercano al abolicionismo, proponiendo el castigo de la explotación sexual en todos los casos. La Acción Común (97/154/JAI), de 24 de febrero de 1997, adoptada por el Consejo sobre la base del artículo K.3 del Tratado de la Unión Europea, relativa a la lucha contra la trata de seres humanos y la explotación sexual de niños, disponía que las legislaciones nacionales deben complementar el concepto de trata con el de explotación sexual entendida como: "a) explotación sexual de una persona que no sea un niño, con fines lucrativos, en la que: -se recurra a la coacción, en particular mediante violencia o amenazas, -se recurra al engaño, o -haya abuso de autoridad u otras formas de presión, de modo tal que la persona carezca de una opción real y aceptable que no sea la de someterse a la presión o abuso de que es objeto". Ingresa así en la Política Criminal europea la finalidad de perseguir toda forma de explotación sexual abusiva.

Por último, la Decisión Marco 2011/36/UE para prevenir y perseguir la trata de seres humanos señala entre las infracciones que los países deben tipificar en sus legislaciones penales, un concepto de explotación en el art. 2.3: "La explotación incluirá, como mínimo, la explotación de la prostitución ajena, u otras formas de explotación sexual, el trabajo o los servicios forzados, incluida la mendicidad, la esclavitud o prácticas similares a la esclavitud, la servidumbre, la explotación para realizar actividades delictivas o la extracción de órganos". Con lo cual puede apreciarse una concepción de explotación sexual amplia de toda forma de explotación de la prostitución ajena u otras formas de explotación sexual, como las vinculadas a la pornografía. 
El legislador de 2015 ha ido aún más lejos realizando una interpretación auténtica de lo que se considera explotación sexual en el delito de determinación a la prostitución del art. 187.1 $\mathrm{CP}$, en el que se castiga toda forma de proxenetismo, incluso con el consentimiento de la persona adulta. Establece: "En todo caso, se entenderá que hay explotación cuando concurra alguna de las siguientes circunstancias: a) Que la víctima se encuentre en una situación de vulnerabilidad personal o económica. b) Que se le impongan para su ejercicio condiciones desproporcionadas, gravosas o abusivas.

El legislador ha querido penalizar el aprovechamiento de las dificultades ajenas para someter a una persona a la prostitución y lucrarse de ello, cuando la persona esté en una situación personal de necesidad. Además, hay una finalidad de objetivar las condiciones de explotación, al margen de la comprobación del consentimiento de la víctima, porque ésta muchas veces no puede declarar con libertad por la misma situación de indefensión en que se encuentra.

Como se ha dicho, son muchos los casos límite donde no resulta fácil determinar si estamos ante un comportamiento contrario a la voluntad de la víctima por su situación personal de la que abusa el tratante o se trata de un acto voluntario ${ }^{62}$. Además, el mundo del ejercicio de la prostitución se realiza dentro del llamado "negocio del sexo", con innumerables formas: clubs de alterne, pornografía, por cuenta propia, por cuenta ajena, salones de masajes, locación de servicios, arrendamientos de lugares, etc., etc. Establecer donde hay explotación sexual y donde no resulta difícil, sobre todo porque por sus propias características estas actividades se realizan de manera clandestina.

Ahora bien, no toda forma de explotación sexual es un delito de trata, lógicamente, puesto que éste es un delito más grave y complejo, con una mayor lesividad. La trata se carac-

62 De la misma opinión PÉREZ ALONSO, "La política europea en materia de trata de seres humanos", ob. cit., p. 31. 
teriza como un proceso o fases, captación, transporte y explotación, siendo la finalidad de explotación (sexual, laboral, etc.) otro delito en sí que merece reproche propio ${ }^{63}$. Pero para determinar este extremo es preciso adentrarnos en algunos aspectos técnicos relevantes.

\section{La tipificación penal de la trata de seres humanos. El bien jurídico protegido}

Ha de convenirse que la influencia de los convenios internacionales en las legislaciones nacionales de los diversos países para tipificar el delito de trata de seres humanos, visibilizarlos y condenarlos, ha sido decisiva. Porque tratándose de "un delito invisible" o que se ha perseguido muy poco, resultaba clave que los códigos penales dieran nombre y concepto a comportamientos que sucedían en nuestra Sociedad ante los ojos impasibles de todos. Muy similarmente a lo que ha sucedido con la violencia de género, hubo que tipificar, es decir, dar nombre y describir con detalle las conductas insoportables de la Sociedad que ya discurrían corrientemente, para empezar a perseguir a los victimarios y proteger a las víctimas. La llamada "trata de blancas" es algo que siempre ha existido, como la explotación de la prostitución, los trabajos forzados, la servidumbre, pero que a ojos de los operadores jurídicos no se percibía como objeto de persecución penal. En efecto, como apuntan los propios operadores jurídicos cercanos a estos delitos o los Informes de Organismos Internacionales y ONGs antes señalados que se ocupan del tema,

63 Cfr. VILlACAMPA ESTIARTE, Carolina, Prostitución: ¿hacia la legalización?, Valencia, Tirant lo Blanch, 2012, p. 232: "la trata constituye un simple mecanismo mediante el cual conseguir esclavizar a las personas, representa la referencia normativa al proceso de esclavización, pero no del resultado de tal proceso, que es en lo que consiste propiamente la esclavitud". Ello se plasma en la legislación penal, en el art. 177.8 bis CP: "En todo caso, las penas previstas en este artículo se impondrán sin perjuicio de las que correspondan, en su caso, por el delito del art. 318 bis de este código y demás delitos efectivamente cometidos, incluidos los constitutivos de la correspondiente explotación". 
las leyes suelen tener problemas técnicos para su aplicación, existen pocas condenas, los funcionarios encargados de aplicar la ley no reconocen en la realidad operativa las situaciones de trata (se confunden con el ejercicio de la prostitución) y, no se observa demasiada eficacia en la persecución de estos delitos.

Analizar cuál es el bien jurídico protegido en el delito de trata resulta crucial porque define los contornos de la lesividad de la conducta y, por tanto, puede favorecer o no la impunidad, con la consiguiente falta de protección a las víctimas. Además, es fundamental para determinar el contenido del elemento "vulnerabilidad de la víctima" que se agrega a los típicos vinculados con el consentimiento de engaño, error, violencia, contemplado en la legislación internacional y la legislación nacional. En definitiva, la determinación del bien jurídico protegido del delito de trata de seres humano resulta clave para la perseguibilidad del mismo.

\section{1. ¿Cuál es el bien jurídico protegido? Validez del consentimiento en estos casos}

Existe un debate sumamente interesante acerca del bien jurídico protegido en este delito, sus alcances y contenido, en el que merece la pena detenerse para comprender los límites de la lesividad de estos comportamientos. Sin duda, la determinación del objeto de protección ayuda a centrar el injusto penal de los comportamientos que se pretenden incluir en el tipo penal y, en definitiva, a ampliar o disminuir la protección de las víctimas.

Hay tres posturas al respecto: 1) Se protege la libertad personal. 2) Se protege la dignidad humana y 3) Se trata de un delito cuya finalidad última es la protección del bien jurídico objeto de explotación (la libertad sexual, delito contra los trabajadores, etc.). Las consecuencias para la protección de los derechos de las víctimas son enormes según se siga una u otra posición. La tercera opción es prácticamente inviable porque iría en contra de todos los convenios internacionales que regulan la trata, en los que se insiste en la gravedad del comportamiento lesivo a los derechos humanos (más allá de un bien jurídico in- 
dividual), el carácter de proceso o fases (su complejidad) en el que se lesionan varios bienes jurídicos (libertad ambulatoria, libertad sexual, derechos laborales, etc.) y la sustantividad de este proceso delictivo como injusto penal con un reproche propio distinto de la propia explotación ${ }^{64}$. Merece detenerse entre las diversas consecuencias de la opción entre libertad y dignidad.

En España pocos autores pueden fundamentar que la trata protege la libertad personal porque la sistemática del delito del art. 177 bis CP, con un encaje propio (un Título propio) y la misma Exposición de Motivos desvelan que detrás de este tipo penal está la protección de la libertad y la dignidad de las personas. El enfoque desde los derechos humanos de las víctimas que se propicia desde el Protocolo de Palermo de 2000 y que siguen los Instrumentos Internacionales dejan ver que la libertad personal, como un atributo del ser humano para decidir bajo la autonomía de la voluntad su propia opción de vida, no puede ser el objeto de protección en el delito de trata, no sólo porque se protege a los menores en todo caso, aún sin los medios coactivos, sino también porque la introducción del medio abusivo (abuso de situación de superioridad o vulnerabilidad) muestra que la voluntad no es un elemento decisorio incluso tratándose de adultos. Cierto es que en los casos de adultos que consienten su explotación sexual de manera clara y evidente no podría existir trata, porque en estos casos el sujeto no estaría siendo cosificado, sino que primaría un derecho fundamental al desarrollo de su libre personalidad.

Ahora bien, aunque no sea mayoritario asumir esta opción de la autonomía de la voluntad en el delito de trata, resulta interesante ver las consecuencias de considerar el bien jurídico protegido libertad personal en el Derecho Comparado. Según la Corte Suprema de Justicia de Perú, el Acuerdo Plenario 3-2011 $\mathrm{CJ} / 116$, párrafo 12: "la trata de personas protege la libertad personal entendida como la capacidad de autodeterminación de una

64 Vid. nota anterior. 
persona para desenvolver su proyecto de vida". Varias sentencias, en esa misma línea, llegan a argumentar que si el menor (en edad penal de consentir su libertad sexual, 14 años) consciente la explotación sexual, no hay lesividad y, por tanto, se han absuelto varios casos que se llevaron a juzgamiento ${ }^{65}$. Esta interpretación ciertamente errónea porque deja sin protección a los niños y por tanto es contraria a todos los convenios internacionales del niño y los referentes a la trata, lo es también incluso en el caso de que el sujeto sea adulto, porque el bien jurídico no es la libertad, es la dignidad como derecho humano básico del que emanan los demás derechos fundamentales. Especialmente sangrante es la desprotección frente a los niños, incluso en los supuestos más arriba mencionados en la Amazonia del Perú en que el propio contexto familiar incita a la trata de niñas. Pero además, esta perspectiva del bien jurídico también permite un enfoque invertido en el proceso de recaudo probatorio. En ambos casos, el resultado es un estándar de protección penal y procesal penal débil de las víctimas de trata de personas ${ }^{66}$.

Siguiendo a VILLACAMPA: "Si la trata de personas debe ser considerado un delito a nivel global, el delito que la incrimina debe ser un valor que goce también de un reconocimiento al mismo nivel" 67 , es decir, un alcance y contenido de derecho humano. Así, la dignidad humana es un bien jurídico capaz de cumplir con ese objetivo de reconocimiento de un derecho humano protegible en cualquier Estado. Ello porque las Cartas Internacionales de los Derechos Humanos reconocen como base de los mismos la dignidad humana. En el mismo sentido MILITELLO, para quien pese a la variedad de manifestaciones actuales de la trata, hay un núcleo común: "la persona humana viene a ser utilizada de manera instrumental por otro sujeto

65 Cfr. MONTOYA VIVANCO, "El delito de trata como delito complejo y sus dificultades en la jurisprudencia peruana”, en ZÚÑIGA RODRÍGUEZ (Dir.), Criminalidad organizada transnacional: una amenaza a los Estados democráticos, Valencia, Tirant lo Blanch, 2017, pp. 481 y ss.

66 Ob. ult. cit., p. 482.

67 VILLACAMPA ESTIARTE, “art. 177 bis”, ob. cit., p. 1111. 
para sacarle cualquier utilidad" ${ }^{98}$. Se trata del reconocimiento del ideal kantiano plasmado en los instrumentos internacionales que el hombre es un fin en sí mismo y ninguna persona puede ser utilizada como medio para los fines de otra. La trata es precisamente esto, la cosificación de la persona, la utilización para fines propios, la negación de la condición básica de persona. Y el Derecho Penal ha de proteger a los más débiles, niños, personas desvalidas en situación de necesidad o vulnerabilidad en todos los casos $^{69}$, pues precisamente el Derecho se erige como el instrumento social para prevenir los abusos y el imperio de la ley del más fuerte.

Considero que en los casos de abuso de situación de necesidad o vulnerabilidad ${ }^{70}$ en que se somete a una persona a situaciones objetivas de explotación, no entra a tallar la libertad de consentir, pues esa persona no está en situación objetiva de decidir ya que se encuentra en un escenario de sometimiento, sino rige la intangibilidad de la dignidad humana, como expresión de la condición de persona ${ }^{71}$. Como sostiene MONTOYA: "tanto el

68 MiLitello, "La tratta di esseri humani: la Politica Criminale multilivello e la problematica distinzione con il traffico di migranti”, ob. cit., p. 90. En p. 91 : « En todos los casos, cualquiera que sea el bien jurídico específicamente tutelado de la correspondiente norma incriminativa, en el fondo está la misma dignidad humana en sus condiciones mínimas".

69 Lo plasma así la Directiva 2011/36/UE relativa a la prevención y lucha contra la trata de seres humanos, en su art. 2.4 dice: "El consentimiento de una víctima de la trata de seres humanos para su explotación, prevista o consumada, no se tendrá en cuenta cuando se haya recurrido a cualquiera de los medios contemplados en el apartado 1 ".

70 Interesante reflexión de MONTOYA VIVANCO, ob. cit., p. 487: "En mi concepto, el caso de víctimas familiares es una especificidad de las víctimas vulnerables, dado que la situación de vulnerabilidad radica en el contexto familiar o doméstico donde el pariente o familiar ejerce un dominio sobre la víctima o abusa de la situación de confianza que ésta deposita en aquel". En América Latina, Asia y África, muchas niñas son vendidas por sus propios padres. Incluso es un fenómeno soterrado dentro de los matrimonios forzados de niñas.

71 Muy próxima ALONSO ÁLAMO, Mercedes, “¿Protección penal de la dignidad? A propósito de los delitos relativos a la prostitución y a la trata de 
contexto asimétrico y vertical que caracteriza la relación entre el sujeto activo y la víctima en la trata de personas, como el fin de explotación de la víctima en este delito (utilización de una persona para fines propios), impiden aceptar la relevancia del consentimiento de la víctima, especialmente cuando se trata de menores de edad" "72. Se observa claramente este argumento en el menor de edad y parece irrebatible. Sin embargo, cuando se trata de mayores de edad pueden saltar las dudas, por lo que conviene ahondar más en la situación objetiva de explotación en estos casos.

Me parece importante resaltar que la situación objetiva de explotación no depende de la voluntad personal en todos los casos. Lo vemos claramente en la explotación laboral. Si se produce una degradación de las condiciones laborales por debajo del umbral que la ley laboral considera como límites irrenunciables (salario, vacaciones, jornadas, etc.), se produce explotación laboral, sin tener en cuenta la voluntad del sujeto que las sufre (que puede aceptarlas por diversas razones, muchas de las veces por necesidad). En estos casos, no es relevante el consentimiento, la autonomía de la voluntad, ni el hecho que la persona tenga una edad que se le considere capaz de decidir. Las condiciones objetivas indican que existe explotación laboral, algo que es indiscutible y conecta con la dignidad humana como derecho humano intangible. Indudablemente será más problemático determinar esta situación en el caso de la explotación sexual en la que no existe, por las razones de clandestinidad que se desarrolla y por no existir una regulación al respecto, la posibilidad de definir un umbral mínimo irrenunciable. No obstante, el juez podrá valorar según las pruebas que tiene a su disposición si objetivamente esa persona ha sido cosificada, utilizada como un

personas para la explotación sexual”, en Revista Penal, № 19, 2007, p. 7. Aunque la autora enfoca la dignidad humana entendida como integridad moral, propio de la condición de persona, irrenunciable y no sometida a la voluntad personal.

72 MONTOYA VIVANCO, ob. cit., p. 501. 
medio para la utilidad personal del tratante, afectando la dignidad personal, más allá de las afirmaciones de consentimiento del tratante y de la supuesta voluntad de las víctimas. Estas últimas, casi siempre por la relación de poder que existe entre sujeto activo y víctima, dirán en el juzgamiento que la explotación sexual se realiza con pleno consentimiento, algo que no es en todos los casos totalmente cierto.

Como se ha insistido a lo largo de este trabajo, en los casos de situación de vulnerabilidad o superioridad no hay coacción explícita, no hay consentimiento explícito, ni oposición a la trata evidente, porque en muchos casos se realizan dentro de prácticas soterradas de explotación. Como bien expresa MONTOYA, "el diagnóstico criminológico antes expuesto ${ }^{73}$, que nos indica que, indistintamente que se trate de un delito cometido en un contexto de criminalidad organizada o se trate de un delito como expresión de prácticas codelincuenciales domésticas e incluso unipersonales, el delito de trata expresa siempre un situación previa o provocada de relación asimétrica de dominio de una persona sobre otra"74. Lo que sucede es que ese dominio a veces se da por la fuerza, pero otras veces se utiliza medios más sutiles como el engaño o el aprovechamiento de una situación de vulnerabilidad. Por tanto, en estos casos lo importante es verificar la situación objetiva de explotación sexual o laboral, donde la expresión de la voluntad está mediatizada por la situación de poder creada. Claro está, si hubiera una expresión de voluntad clara y rotunda de persona adulta de consentimiento, en la que no existiera situación de vulnerabilidad, primaría el derecho fundamental al libre desarrollo de la personalidad. Pero lo importante es que en situaciones de explotación objetiva no basta con testimonios, pruebas sobre la voluntad de ambas partes, sino se requiere una investigación seria para verificar si existen

73 Se refiere a los estudios antes mencionados (nota X) sobre la trata en la Amazonia peruana, pero son perfectamente trasladables a muchas situaciones de África, Asia, Europa del Este, regiones pobres desde donde provienen las mujeres tratadas en Europa.

74 MONTOYA VIVANCO, ob. cit., p.491. 
dichas situaciones objetivas de explotación sexual, donde no es suficiente el testimonio de la víctima sobre su consentimiento, dado que detrás está la protección de un derecho humano y la protección a las víctimas de no ser cosificadas. Las circunstancias descritas en el art. 187.1 CP bien pueden alumbrar dichas situaciones objetivas: a) Que la víctima se encuentre en una situación de vulnerabilidad personal o económica. b) Que se le impongan para su ejercicio condiciones desproporcionadas, gravosas o abusivas.

En la jurisprudencia italiana la definición de vulnerabilidad es "cualquier situación de debilidad o carencia material o moral atada a condicionar la voluntad de la persona". Asimismo, el art. 2, pár. $3^{\circ}$ de la Directiva de 2011 define la vulnerabilidad como "una situación en la que la persona en cuestión no tiene otra efectiva y aceptable elección si no acceder al abuso de que es víctima". Entonces, deviene relevante cuando el sujeto explota dichas debilidades que influyen en la capacidad de autodeterminación del sujeto ${ }^{75}$.

En sentido similar se expresan los fiscales argentinos COLOMBO y MÁNGANO, para quienes también en el delito de trata al proteger la dignidad humana, no cabe el consentimiento. Por tanto, "medios como el abuso de autoridad o de una situación de vulnerabilidad y la concesión o recepción de $\mathrm{p}$ agos o beneficios para obtener el consentimiento de una persona que tenga autoridad sobre la víctima, se presentan como supuestos de una voluntad ya doblegada de antemano por el marco de una clara restricción de su ámbito de determinación" ${ }^{76}$.

75 Cfr. Militello, "La tratta di esseri humani: la Politica Criminale multilivello e la problematica distinzione con il traffico di migranti”, ob. cit., p. 107. Este autor va más allá, sosteniendo que precisamente este puede ser el elemento de unión entre las dos conductas próximas de inmigración ilegal y trata.

76 COLOMBO y MÁNGANO, "El consentimiento de la víctima en la trata de personas y un análisis de los medios comisivos previstos en la figura penal", en Revista del Ministerio Público, Año 7, Núm. 11, 2010, p. 1, https://www. mpba.gov.ar/revista/RevistaNro11-web.pdf. 
Parece que el elemento más problemático de definir entre todos, es precisamente el de vulnerabilidad, por ello Naciones Unidas ha propuesto elaborar unos indicadores de las condiciones de la vulnerabilidad en relación con los temas siguientes: la niñez, el género, la pobreza, la exclusión social y cultural, la educación limitada, la inestabilidad política, la guerra y los conflictos, los marcos sociales, culturales y jurídicos, el desplazamiento impuesto por coacción y la demanda ${ }^{77}$. Para estos autores, esta serie de factores - de carácter externo o interno - de presentarse en el caso concreto, constituirán presunciones iuris tantum de que el autor se ha valido fundamentalmente de ellos para obtener el doblegamiento de la víctima para su explotación. "Lo central, como en todo delito, será además evaluar la conducta del autor - o del sospechado - para establecer qué conocimiento tenía respecto de la situación en que la víctima se encontraba $\cdot{ }^{78}$.

Ciertamente que las presunciones en Derecho Penal no son admisibles, pero lo curioso es que desde los operadores jurídicos que están en el terreno de la trata, hay acuerdos en objetivar las situaciones de vulnerabilidad al margen de los testimonios de víctima y autor, pues suelen ser falsos.

En suma, vulnerabilidad, respeto a la dignidad humana, protección a las víctimas de trata y objetivación de las situaciones de explotación sexual o laboral, más allá del falso libre consentimiento, parecen caminos necesarios de recorrer para una adecuada protección de las víctimas de trata, bajo un Derecho Penal protector del más débil.

\section{Conclusiones}

1. La trata de seres humanos es un fenómeno complejo, poliédrico, en el que recurrentemente se encuentran ambivalencias, intereses contrapuestos, que dificultan su per-

77 Ob. ult. cit., de acuerdo con la Oficina de las Naciones Unidas, "An Introduction to Human Trafficking: Vulnerability, Impact and Action”, p. 21.

78 Ob. ult. cit., p. 22.0 
secución. Las definiciones de la ley, con su necesidad de establecer generalizaciones, abstracciones, parecen olvidar situaciones concretas, voluntades personales. Nos encontramos en muchos supuestos de casos límites, donde no es fácil saber la voluntariedad del comportamiento de la persona tratada. También es un fenómeno invisible, donde no se encuentran estadísticas, o estas son dispares, con escasa perseguibilidad e ínfimos castigos.

2. Las dificultades del tratamiento político-criminal de la trata de seres humanos con fines de explotación sexual se centran en sus vinculaciones con otros fenómenos como la inmigración clandestina, la prostitución y la explotación sexual, cuya licitud e ilicitud varía de un país a otro y donde encontramos claro-oscuros difíciles de dilucidar en la realidad.

3. El concepto de vulnerabilidad de la víctima de trata ha resultado controvertido. Para un sector del feminismo el discurso de la vulnerabilidad esconde un tratamiento de la mujer que ejerce la prostitución como un ser débil, sin capacidad de voluntad. Sin embargo, los relatores de los acuerdos internacionales inciden en que estas conductas no solo se realizan con violencias explícitas, sino en muchísimos casos existen abusos de situación de superioridad, como sucede con padres, maestros, autoridades, o abuso de situación de vulnerabilidad, cuando el tratante se aprovecha de la situación de pobreza, marginalidad, incapacidad para sobrevivir. En estos supuestos las víctimas no tienen capacidad de elección, tampoco existe una oposición clara frente a la explotación.

4. Creo que no puede presumirse que todo ejercicio de la prostitución es coactivo, pero tampoco puede presumirse que todo ejercicio de la prostitución es libre. En la realidad existen muchos supuestos en que el ejercicio de la prostitución de adulta esconde explotación sexual cercana a la trata de seres humanos. Feminización, pobreza, inmi- 
gración clandestina y marginalidad se suelen asociar en la práctica de la prostitución, donde no queda siempre clara la autonomía de la voluntad. Como no reconocer la vulnerabilidad en la que se encuentran muchas mujeres y niños, normalmente los más golpeados por la pobreza en el mundo. Prueba de ello es que los datos sobre trata que revelan los informes internacionales inciden en que las víctimas suelen provenir de los países más pobres de la tierra, sin contar con la trata interna que normalmente se realiza de zonas pobres a zonas ricas dentro de los propios países.

5. Siguiendo a VILLACAMPA, si la trata de personas debe ser considerado un delito a nivel global, el delito que la incrimina debe ser un valor que goce también de un reconocimiento al mismo nivel, es decir, un alcance y contenido de derecho humano. Así, la dignidad humana es un bien jurídico capaz de cumplir con ese objetivo de reconocimiento de un derecho humano protegible en cualquier Estado. La trata es precisamente esto, la vulneración de la dignidad humana, la cosificación de la persona, la utilización para fines propios, la negación de la condición básica de persona. Y el Derecho Penal ha de proteger a los más débiles, personas desvalidas en situación de necesidad o vulnerabilidad en todos los casos.

6. Desde el punto de vista criminológico, la trata de personas expresa una relación asimétrica, de dominio entre tratante y tratada, en la que existen unas condiciones objetivas de explotación, situaciones en las que es difícil percibir la autonomía de la voluntad. Esto es, más allá de los medios iniciales para hacer entrar a la víctima en la lógica del tratante, lo realmente grave es ese dominio permanente que ejerce el victimario, instrumentalizando a la persona para sus fines propios, el cosificar a la persona, en degradar su libertad a cero.

7. Por tanto, en situaciones de explotación objetiva, aprovechamiento de una situación de vulnerabilidad, no basta 
con testimonios sobre la voluntad de ambas partes, sino se requiere una investigación seria para verificar si existen dichas situaciones objetivas de explotación sexual, donde no es suficiente la declaración de la víctima sobre su consentimiento, dado que detrás está la protección de un derecho humano y la obligación internacional de protección a las víctimas de no ser cosificadas.

\section{BIBLIOGRAFÍA}

ALONSO ÁLAMO, “¿Protección penal de la dignidad? A propósito de los delitos relativos a la prostitución y a la trata de personas para la explotación sexual", en Revista Penal, $\mathrm{N}^{\circ} 19,2007$.

BOZA MORENO, Sobre la prostitución. Un análisis desde la política criminal y su necesidad de legalización, Tesis Doctoral, Universidad Pablo de Olavide, 2017.

CASTELLS, La era de la información. Fin de milenio. Vol. 3, Barcelona, Alianza Editorial, 2001.

COLOMBO y MÁNGANO, "El consentimiento de la víctima en la trata de personas y un análisis de los medios comisivos previstos en la figura penal", en Revista del Ministerio Público, Año 7, Núm. 11, 2010, https://www.mpba. gov.ar/revista/RevistaNro11-web.pdf

DAUNIS RODRÍGUEZ, La trata de seres humanos, Valencia, Tirant lo Blanch, 2013.

DAUNIS RODRÍGUEZ, "La inmigración ante la encrucijada: el tráfico de personas, la trata de seres humanos y la explotación sexual", en ZÚÑIGA RODRÍGUEZ (Dir.), Criminalidad organizada transnacional: una amenaza a los Estados democráticos, Valencia, Tirant lo Blanch, 2017.

DE LA CORTE IBÁÑEZ / JIMÉNEZ-SALINAS, Crimen.org: evolución y claves de la delincuencia organizada, Ariel, 2010.

DE LA CUESTA ARAZAMENDI, "Las nuevas corrientes internacionales en materia de persecución de delitos sexuales 
a la luz de los documentos de organismos internacionales y europeos", en DIEZ RIPOLLÉS, Delitos contra la libertad sexual, Estudios de Derecho Judicial, Madrid, 1999, publicado en la red: http://www.ehu.eus/documents/1736829/2010409/CLC+45+Las+nuevas+corrien tes+internacionales+materia + persecucion.pdf

FERRAJOLI, Derechos y garantías. La ley del más débil, Madrid, Trotta, 1999.

GIMÉNEZ-SALINAS / REQUENA / DE LA CORTE, “¿Existe un perfil de delincuente organizado?, en Revista electrónica de Derecho Penal y Criminología, No 13, 202011, en http://criminet.ugr.es/recpc

JULIANO, "Transformaciones de la prostitución y del trabajo sexual en la era de la industria del sexo", en IGLESIAS SKULJ / PUENTE ABA, Sistema penal y perspectiva de género: trabajo sexual y trata de personas, Valencia, Tirant lo Blanch, 2012.

LORENTE-MOLINA, "Otredad, marginación y política en la prostitución", en LAURENZO COPELLO / DAUNIS RODRIGUEZ, Colectivos en los márgenes del Derecho, Valencia, Tirant lo Blanch, 2016.

MAQUEDA ABREU, "Cuando el discurso sobre la vulnerabilidad se convierte en un discurso ideológico (A propósito de las "víctimas" de la prostitución y el tráfico sexual de mujeres", en PÉREZ ÁLVAREZ (Ed.), Serta, In memoriam Louk Houlsman, Ediciones Universidad de Salamanca, 2015.

MINTJAS / MOLNAR, “Trabajadoras sexuales: víctimas de la exclusión. Estudio sobre la victimización de las trabajadoras sexuales en la provincia de Málaga, en LAURENZO COPELLO / DAUNIS RODRIGUEZ, Colectivos en los márgenes del Derecho, Valencia, Tirant lo Blanch, 2016.

MILITELLO, "La tratta di esseri humani: la Politica Criminale multilivello e la problematica distinzione con il traffico di migranti”, en Rivista italiana di Diritto e Procedure Penale, Anno LXI - Fasc. 1, 2018. 
MONTOYA VIVANCO, "El delito de trata de personas como delito complejo y sus dificultades en la jurisprudencia peruana, en ZÚÑIGA RODRÍGUEZ (Dir.), Criminalidad organizada transnacional: una amenaza a los Estados democráticos, Valencia, Tirant lo Blanch, 2017.

MUJICA, "Trayectorias y ciclos de explotación sexual y trata para la explotación sexual de mujeres en la Amazonía peruana", en ANTHROPOLOGICA, Año XXXII, N. ${ }^{\circ} 33$, 2014, pp. 163-177.

MUJICA y CAVAGNOUD, "Mecanismos de explotación sexual de niñas y adolescentes en los alrededores del puerto fluvial de Pucallpa", en ANTHROPOLOGICA, Año XXIX, $\mathrm{N}^{\circ} 29$, diciembre de 2011.

PÉREZ ALONSO, "La Política Criminal europea en materia de trata de seres humanos", Revista de la Facultad de Derecho de la Universidad de Granada, No 16-17, 2013-2014.

PÉREZ CEPEDA, Globalización, tráfico internacional ilícito de personas y derecho penal, Granada, Comares, 2004.

VILLACAMPA ESTIARTE, “art. 177 bis”, QUINTERO OLIVARES (Dir.), Comentarios al Código Penal español, Navarra, Aranzadi, 2011.

VILLACAMPA, Carolina, "Análisis de las políticas de criminalización de la prostitución", en IGLESIAS SKULJ / PUENTE ABA, Sistema penal y perspectiva de género: trabajo sexual y trata de personas, Valencia, Tirant lo Blanch, 2012.

VILLACAMPA ESTIARTE, Carolina, Prostitución: ¿hacia la legalización?, Valencia, Tirant lo Blanch, 2012. 